\title{
A Single-Bridge Strategy for Synthesis of a 3-D Heterobimetallic Cluster with a Heavily Distorted Diamondoid Topology and Enhanced Third-Order Nonlinear Optical Properties
}

\author{
Jinfang Zhang, ${ }^{\dagger}$ Yinglin Song, ${ }^{\ddagger}$ Junyi Yang, ${ }^{\ddagger}$ Mark G. Humphrey, ${ }^{*}{ }^{\S}$ and Chi Zhang*,† \\ Institute of Molecular Engineering and Advanced Materials, School of Chemical Engineering, Nanjing \\ University of Science and Technology, Nanjing 210094, P. R. China, School of Physical Science and \\ Technology, Suzhou University, Suzhou 215006, P. R. China, and Department of Chemistry, \\ Australian National University, Canberra, Australian Capital Territory 0200, Australia
}

$387-390$

Received September 12, 2007; Revised Manuscript Received October 23, 2007

\begin{abstract}
A novel three-dimensional heterobimetallic cluster $\left\{\left[\mathrm{Bu}_{4} \mathrm{~N}\right]\left[\mathrm{WS}_{4} \mathrm{Cu}_{3}(\mathrm{CN})_{2}\right]\right\}_{n}(\mathbf{1})$ with a heavily distorted diamondoid topology was constructed from the T-shaped building clusters $\left[\mathrm{WS}_{4} \mathrm{Cu}_{3}\right]^{+}$and single cyanide bridges in a 4-connected mode; this cluster shows strong third-order nonlinear optical properties.
\end{abstract}

The design and synthesis of multidimensional coordination compounds have continued to attract considerable interest for both the intriguing architectures and the physical properties of the resultant materials. ${ }^{1} \mathrm{M} / \mathrm{S} / \mathrm{Cu}(\mathrm{M}=\mathrm{Mo}, \mathrm{W})$ clusters have long been explored for their diverse coordination modes and potential applications, particularly in third-order nonlinear optical (NLO) materials. ${ }^{2-4}$ Although a rich variety of ligands and building units have been used to synthesize $\mathrm{M} / \mathrm{S} / \mathrm{Cu}$ clusters, ${ }^{2,4}$ crystal engineering of multidimensional clusters with well-defined geometries still faces great challenges to control the complexity and diversity of the frameworks. ${ }^{4}$ It is noteworthy that multidimensional M/S/Cu cluster frameworks are usually constructed from double-bridging ligands, which has limited both the fabrication of such polymeric clusters and the diversity of cluster architecture $;^{4-9}$ to the best of our knowledge, except for "planar" open clusters $\left[\mathrm{MS}_{4} \mathrm{Cu}_{4}\right]^{2+}$ and the nest-shaped cluster $\left[\mathrm{WOS}_{3} \mathrm{Cu}_{3}\right]^{+},{ }^{6-9}$ no three-dimensional (3-D) $\mathrm{M} / \mathrm{S} / \mathrm{Cu}$ clusters have thus far been constructed using other building units. In contrast to double-bridging ligands, single bridges can play a unique role in the construction of multidimensional $\mathrm{M} / \mathrm{S} / \mathrm{Cu}$ clusters; for example, the first two-dimensional (2-D) W/S/Cu cluster, constructed from the linear building clusters $\left[\mathrm{WS}_{4} \mathrm{Cu}_{2}\right]$, is connected by single cyanide bridges. ${ }^{5 b}$ These aforementioned investigations inspired us to explore a single-bridge strategy for the generation of novel 3-D M/S/Cu clusters, employing building clusters other than $\left[\mathrm{MS}_{4} \mathrm{Cu}_{4}\right]^{2+}$ and $\left[\mathrm{WOS}_{3} \mathrm{Cu}_{3}\right]^{+}$. We report herein a novel 3-D cluster $\left\{\left[\mathrm{Bu}_{4} \mathrm{~N}\right]\left[\mathrm{WS}_{4} \mathrm{Cu}_{3}(\mathrm{CN})_{2}\right]\right\}_{n}$ (1) with a heavily distorted diamondoid network, which is linked through single cyanide bridges only, the first 3-D example of $\mathrm{Mo}(\mathrm{W}) / \mathrm{S} / \mathrm{Cu}$ clusters constructed by the 4-connected T-shaped building clusters $\left[\mathrm{WS}_{4} \mathrm{Cu}_{3}\right]^{+}$. Z-scan studies of $\mathbf{1}$ reveal strong third-order NLO properties.

The reaction of $\left(\mathrm{NH}_{4}\right)_{2} \mathrm{WS}_{4}$ and $\mathrm{CuBr}$ (molar ratio of 1:3) in dimethylformamide (DMF) led to an orange-red solution. After stirring and filtration and then layering the filtrate with a solution of $\left(\mathrm{Bu}_{4} \mathrm{~N}\right) \mathrm{CN}$ in $i$-PrOH for several days, $\mathbf{1}$ was obtained as orangered block crystals (yield: $36 \%$ based on $\mathrm{W}$ ). ${ }^{10} \mathrm{X}$-ray crystallographic analysis revealed that $\mathbf{1}$ crystallizes in the tetragonal chiral space group $P_{4} 22_{1} 2,{ }^{11}$ and each $\left[\mathrm{WS}_{4} \mathrm{Cu}_{3}\right]^{+}$in $\mathbf{1}$ is linked by another four $\left[\mathrm{WS}_{4} \mathrm{Cu}_{3}\right]^{+}$units through single cyanide bridges to furnish a novel 3-D framework (Figure 1).

* Corresponding authors: (C.Z.) Tel: 86-25-84318257. Fax: 86-25-84315438 E-mail: chizhang@mail.njust.edu.cn. (M.G.H.) Tel: 61-2-61252927. Fax: 61-261250760. E-mail: mark.humphrey@anu.edu.au.

Nanjing University of Science and Technology.

Suzhou University

$\S$ Australian National University.
As shown in Figure 2a, the building cluster $\left[\mathrm{WS}_{4} \mathrm{Cu}_{3}\right]^{+}$with a 4-connected mode exhibits $C_{2}$ symmetry. $\mathrm{Cu} 2-\mathrm{W} 1-\mathrm{Cu} 2 \mathrm{a}$ and $\mathrm{Cu} 2-\mathrm{W} 1-\mathrm{Cu} 1$ angles are $177.67(13)^{\circ}$ and $88.83(6)^{\circ}$, respectively, giving rise to a nearly $\mathrm{T}$-shaped arrangement for each building cluster $\left[\mathrm{WS}_{4} \mathrm{Cu}_{3}\right]^{+}$. In each $\left[\mathrm{WS}_{4} \mathrm{Cu}_{3}\right]^{+}$, three $\mathrm{Cu}$ atoms have two kinds of coordination environments; one is coordinated by two $\mu_{3}-\mathrm{S}$ and two cyanide bridges, forming a tetrahedral geometry, and another two have a triangular coordination geometry formed by one $\mu_{2}-\mathrm{S}$, one $\mu_{3}-\mathrm{S}$ atom, and one cyanide bridge. The $\mathrm{W}$ atom possesses a tetrahedral coordination geometry through bonding to two $\mu_{2}-\mathrm{S}$ and two $\mu_{3}-\mathrm{S}$ atoms, with the $\mathrm{S}-\mathrm{W}-\mathrm{S}$ angles ranging from $107.5(2)$ to $111.1(2)^{\circ}$. The bond lengths of $\mathrm{Cu}-\mu_{2}-\mathrm{S}(\mathrm{Cu} 2-\mathrm{S} 1$, 2.230 (7) $\AA$ ) are comparable to those of $\mathrm{Cu}-\mu_{3}-\mathrm{S}(\mathrm{Cu} 2-\mathrm{S} 2,2.235(6)$ $\AA$; $\mathrm{Cu} 1-\mathrm{S} 2,2.333(5) \AA)$, while bond lengths of $\mathrm{W}-\mu_{2}-\mathrm{S}(\mathrm{W} 1-\mathrm{S} 1$, $2.187(5) \AA$ ) are shorter than those of $\mathrm{W}-\mu_{3}-\mathrm{S}$ (W1-S2, 2.234(4) $\AA$ ), which leads to the expected shortening of the $\mathrm{W} 1 \cdots \mathrm{Cu} 2$ distance $(2.650(2) \AA$ ) in comparison with the $\mathrm{W} 1 \cdots \mathrm{Cu} 1$ distance (2.740(3) ^).

Network analysis of $\mathbf{1}$ reveals that the short vertex symbol of $\mathbf{1}$ is $6^{6}$, the same as those of 3-D M/S/Cu clusters with diamondoid topological networks that were constructed from $\left[\mathrm{MS}_{4} \mathrm{Cu}_{4}\right]^{2+}$ and $\left[\mathrm{WOS}_{3} \mathrm{Cu}_{3}\right]^{+}{ }^{6,8,9}$ Because of the T-shaped arrangement of each building cluster $\left[\mathrm{WS}_{4} \mathrm{Cu}_{3}\right]^{+}, \mathbf{1}$ shows an irregular 3-D 4-connected network (Figure $2 b$ ). All 6-membered rings possess highly distorted chair forms, ${ }^{12}$ which results in a heavily distorted diamondoid topological network for $\mathbf{1}$.

The packing diagram in Figure 1 exhibits two kinds of irregular shaped channels, while both the building clusters and channels show an unusual $\mathrm{ABCD}$ stacking manner. One-dimensional (1-D) squarelike channels can be seen down the $c$-axis (Figure 3a), while viewed along the $a$ - or $b$-axis, the packing diagram of 1 reveals 1-D peanutshaped channels (Figure 3b). Interestingly, examining the [100], [010], and [001] planes of $\mathbf{1}$ (Figure 3) shows that the channels in every two adjacent layers adopt different stacking behavior, in contrast to adjacent channels in the [111] plane which stack in the same manner (Figure S2, Supporting Information).

T-shaped building clusters $\left[\mathrm{MS}_{4} \mathrm{Cu}_{3}\right]^{+}(\mathrm{M}=\mathrm{Mo}, \mathrm{W})$ have been used previously to construct polymeric $\mathrm{M} / \mathrm{S} / \mathrm{Cu}$ clusters (for example, $\left\{\left[\mathrm{Et}_{4} \mathrm{~N}\right]_{2}\left[\mathrm{WS}_{4} \mathrm{Cu}_{3}(\mathrm{SCN})_{3}\right]\right\}_{n} \mathbf{a}^{13}$ and $\left\{\left[\mathrm{PPh}_{4}\right]\left[\mathrm{WS}_{4} \mathrm{Cu}_{3^{-}}\right.\right.$ $\left.\left.\left.(\mathrm{CN})_{2}\right] \cdot \mathrm{MeCN}\right\}_{n} \mathbf{b}^{5 \mathrm{~b}}\right)$. However, each $\left[\mathrm{WS}_{4} \mathrm{Cu}_{3}\right]^{+}$in $\mathbf{a}$ is linked through double bridges that form an infinite 1-D chain, while the building clusters in $\mathbf{b}$ are connected by both single and double bridges, resulting in an infinite 2-D network. In the present study, the same building clusters as those in $\mathbf{a}$ and $\mathbf{b}$ are assembled to construct the new 3-D framework of $\mathbf{1}$ via single bridges only. In particular, $\mathbf{b}$ possesses the same anionic composition as $\mathbf{1}$, but has a 2-D rather than a 3-D structure because of the presence of some 


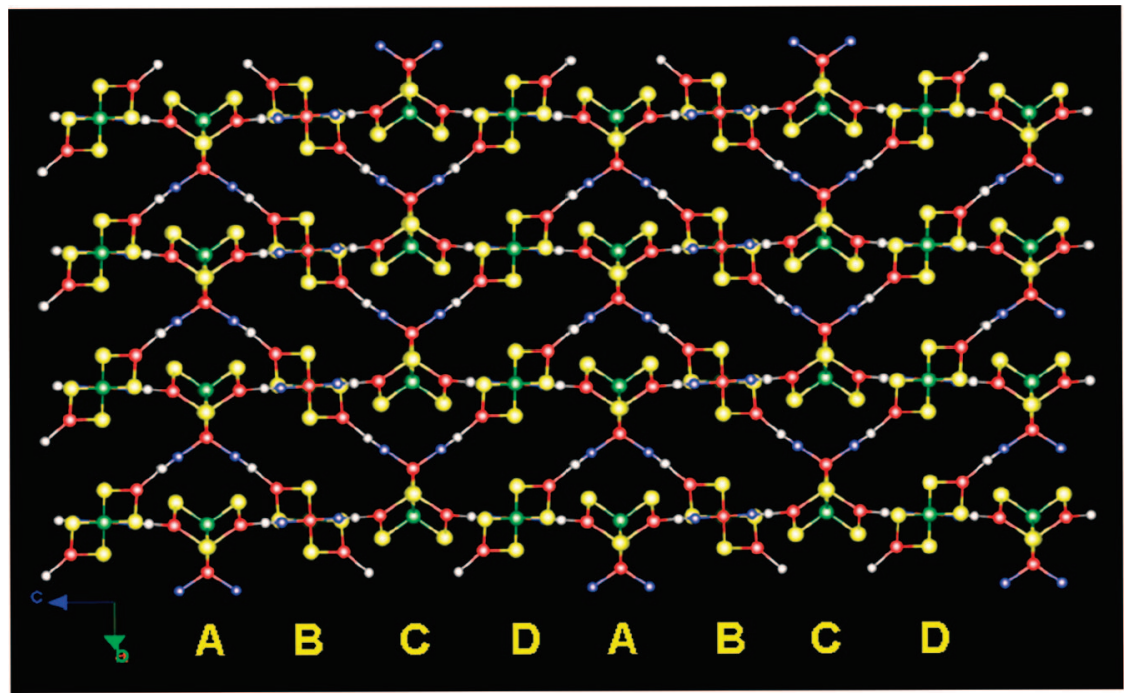

Figure 1. Packing diagram of $\mathbf{1}$ (ball-and-stick representation), showing each T-shaped building cluster in a 4-connected topology and channels in an $\mathrm{ABCD}$ stacking manner (cations of $\mathbf{1}$ are omitted for clarity; S yellow, $\mathrm{C}$ grey, $\mathrm{N}$ blue, Cu red, W green).

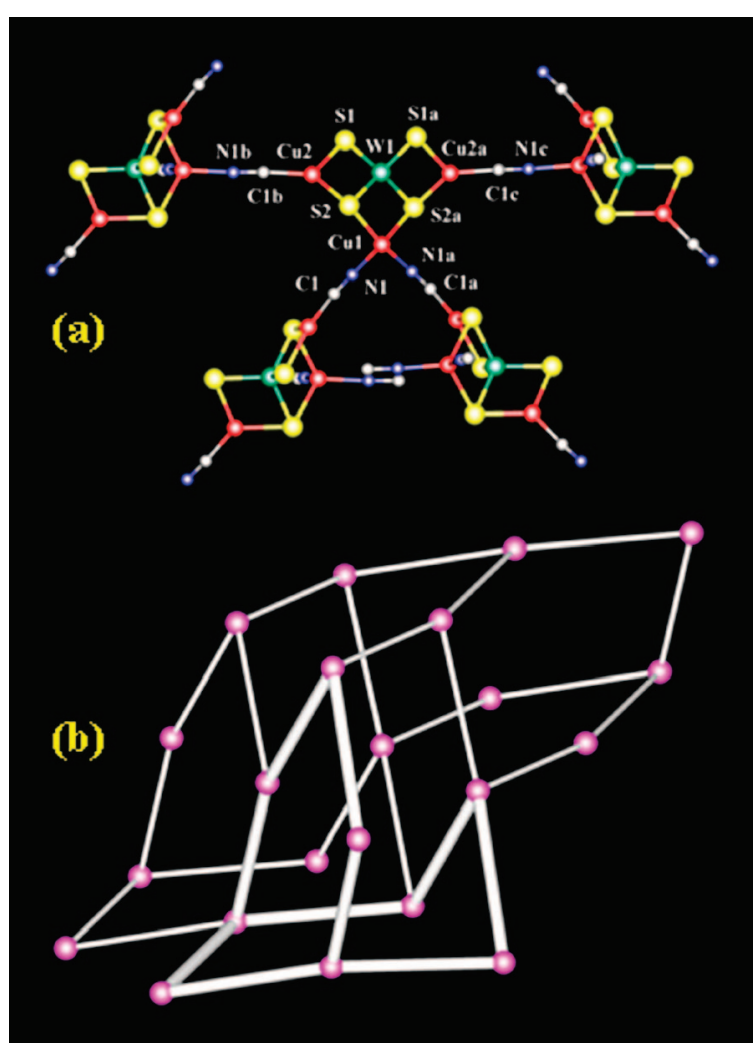

Figure 2. (a) Partial view of the 3-D anionic ball-and-stick plot for 1, showing the 4-connected mode of the T-shaped building cluster $\left[\mathrm{WS}_{4} \mathrm{Cu}_{3}\right]^{+}$(S yellow, $\mathrm{C}$ grey, $\mathrm{N}$ blue, $\mathrm{Cu}$ red, $\mathrm{W}$ green); (b) a fragment of the heavily distorted diamondoid network emphasizing two sixmembered rings; the pink balls and white sticks represent the T-shaped building clusters $\left[\mathrm{WS}_{4} \mathrm{Cu}_{3}\right]^{+}$and single cyanide bridges, respectively.

double bridges. The single-bridging ligands clearly play a crucial role in the generation of the 3-D framework of $\mathbf{1}$. Clusters with larger connectivity numbers afford more complex and diverse frameworks; for example, $\mathrm{M} / \mathrm{S} / \mathrm{Cu}$ clusters with a 3-connected mode tend to form 2-D network structures, ${ }^{5 b}$ while clusters in a 4-connected mode usually form 3-D frameworks. ${ }^{6-9}$ From a topological perspective, building units of multidimensional M/S/ $\mathrm{Cu}$ clusters will have larger connectivity numbers when linked in

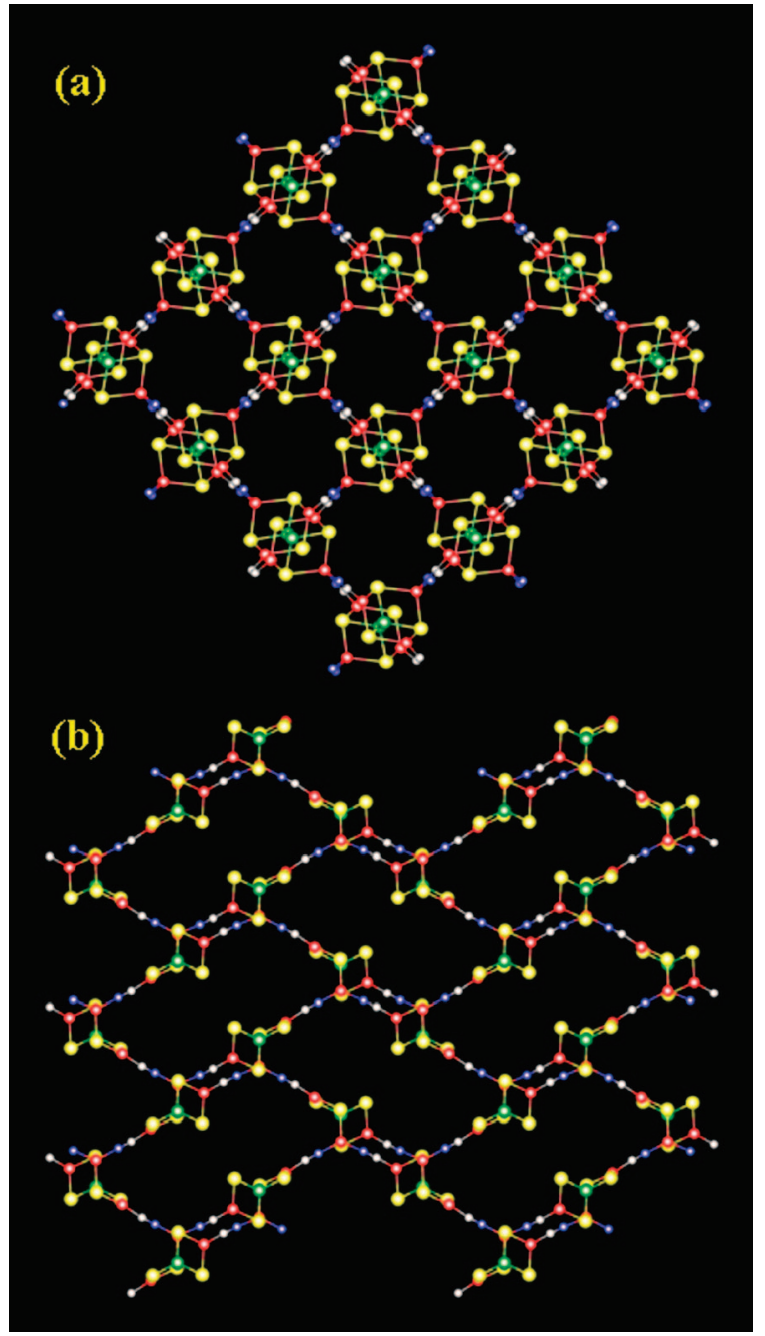

Figure 3. Packing diagram of $\mathbf{1}$ (ball-and-stick representation), viewed along (a) the $c$-axis and (b) the $a$ - or $b$-axis, showing the interlaced square-like and peanut-shaped channels, respectively (cations of $\mathbf{1}$ are omitted for clarity; $\mathrm{S}$ yellow, $\mathrm{C}$ grey, $\mathrm{N}$ blue, $\mathrm{Cu}$ red, $\mathrm{W}$ green).

a single-bridge manner than the same building units linked in a double-bridge manner. Thus, 1 possesses a 3-D framework because 

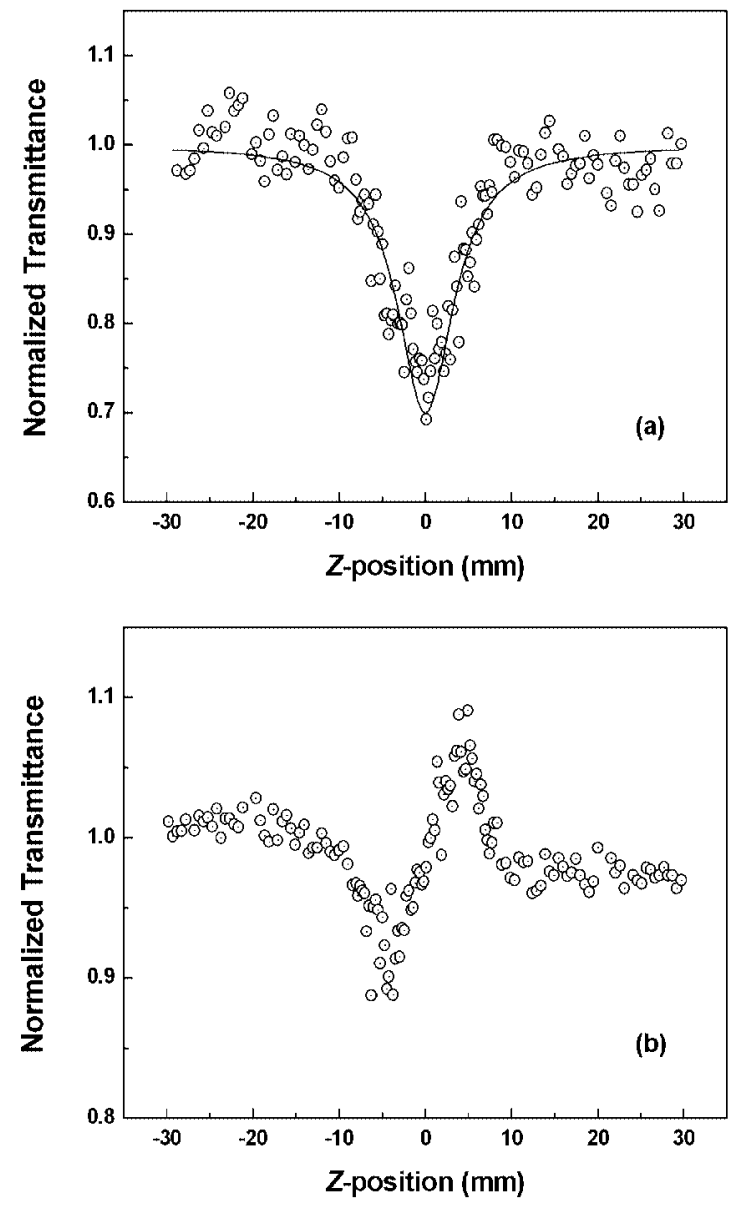

Figure 4. Z-scan measurement of $\mathbf{1}$ in $5.33 \times 10^{-4} \mathrm{~mol} \mathrm{dm}^{-3} \mathrm{DMF}$ solution at $532 \mathrm{~nm}$ : (a) data collected under the open-aperture configuration; (b) data obtained by dividing the normalized $Z$-scan data obtained under the closed-aperture configuration by the normalized $Z$-scan data in (a).

of its T-shaped building clusters in a 4-connected mode, which benefits from the single-cyanide-bridge connection; this differs from a and $\mathbf{b}$, which have 1-D and 2-D frameworks for their 2- and 3 -connected modes, respectively. This may imply that a singlebridge strategy using building clusters other than $\left[\mathrm{MS}_{4} \mathrm{Cu}_{4}\right]^{2+}$ and $\left[\mathrm{WOS}_{3} \mathrm{Cu}_{3}\right]^{+}$should be effective for the construction of new 3-D $\mathrm{M} / \mathrm{S} / \mathrm{Cu}$ clusters with a variety of intriguing geometries.

The third-order NLO absorptive and refractive properties of $\mathbf{1}$ were measured by the $Z$-scan method ${ }^{14}$ with linearly polarized 4.5 ns pulses at $532 \mathrm{~nm}$ generated from a $Q$-switched frequency-doubled $\mathrm{Nd}$ :YAG laser, showing that $\mathbf{1}$ has strong effective third-order NLO absorptive and refractive properties, as illustrated in Figure 4. The nonlinear absorption component was evaluated under an openaperture configuration, and the nonlinear refractive property was assessed by dividing the normalized $Z$-scan data obtained under the closed-aperture configuration by the normalized $Z$-scan data obtained under the open-aperture configuration. The valley/peak pattern of the corrected transmittance curve shows that $\mathbf{1}$ exhibits self-focusing behavior. The NLO absorptive coefficient $\alpha_{2}$ of $\mathbf{1}$ was calculated to be $(7.5 \pm 0.6) \times 10^{-11} \mathrm{~m} \mathrm{~W}^{-1}$. With the measured value of the difference in the normalized transmittance values at the valley and peak positions, the NLO refractive index $n_{2}$ was calculated to be $(1.2 \pm 0.1) \times 10^{-11}$ esu. In accordance with the observed $\alpha_{2}$ and $n_{2}$ values, the modulus of the effective third-order susceptibility $\chi^{(3)}$ was calculated to be $(3.6 \pm 0.3) \times 10^{-12}$ esu; the corresponding modulus of the hyperpolarizability $\gamma$ of $(3.4 \pm$ $0.3) \times 10^{-30}$ esu was obtained from $\chi^{(3)}=\gamma N F^{4}$, where $N$ is the number density (concentration) of cluster in the sample solution and $F^{4}=3.3$ is the local field correction factor. The hyperpolar- izability $\gamma$ of $\mathbf{1}$ is larger than those of many other heterobimetallic chalcogenide clusters with different cluster skeletons (for representative examples, see Table S1, Supporting Information ${ }^{15}$ ), which indicates that $\mathbf{1}$ will be a promising candidate for NLO materials.

In conclusion, by exploiting single-cyanide bridges and T-shaped building clusters, we have successfully constructed a novel 3-D $\mathrm{W} / \mathrm{S} / \mathrm{Cu}$ cluster with a heavily distorted diamondoid topology. In contrast to double bridges, single bridges can link the same building clusters to form more complex and diverse frameworks. Further studies of the formation of new multidimensional heterobimetallic clusters constructed by various single bridges and building clusters are currently in progress.

Acknowledgment. Financial support from the National Natural Science Foundation of China (No. 50472048), Program for New Century Excellent Talents in University (NCET-05-0499, NCET04-0333), and the Australian Research Council (ARC) is acknowledged. M.G.H. is an ARC Australian Professorial Fellow.

Supporting Information Available: Experimental section; optical and other characterization measurements and preparation; Figure S1, Figure S2, and Table S1; X-ray crystallographic file in CIF format for 1. This information is available free of charge via the Internet at http:// pubs.acs.org.

\section{References}

(1) (a) Wang, Z. Q.; Kravtsov, V. C.; Zaworotko, M. J. Angew. Chem., Int. Ed. 2005, 44, 2877. (b) Huang, X. C.; Lin, Y. Y.; Zhang, J. P.; Chen, X. M. Angew. Chem., Int. Ed. 2006, 45, 1557. (c) Eddaoudi, M.; Moler, D. B.; Li, H. L.; Chen, B. L.; Reineke, T. M.; O'Keeffe, M.; Yaghi, O. M. Acc. Chem. Res. 2001, 34, 319. (d) Evans, O. R.; Lin, W. B. Acc. Chem. Res. 2002, 35, 511. (e) Oh, M.; Carpenter, G. B.; Sweigart, D. A. Acc. Chem. Res. 2004, 37, 1.

(2) (a) Zhang, C.; Jin, G. C.; Chen, J. X.; Xin, X. Q.; Qian, K. P. Coord. Chem. Rev. 2001, 213, 51. (b) Hou, H. W.; Xin, X. Q.; Shi, S. Coord. Chem. Rev. 1996, 153, 25.

(3) (a) Zhang, C.; Song, Y. L.; Wang, X. Coord. Chem. Rev. 2007, 251, 111. (b) Müller, A.; Diemann, E.; Jostes, R.; Bogge, H. Angew. Chem., Int. Ed. Engl. 1981, 20, 934. (c) Lee, S. C.; Holm, R. H. Chem. Rev. 2004, 104, 1135. (d) Shi, S.; Ji, W.; Tang, S. H.; Lang, J. P.; Xin, X. Q. J. Am. Chem. Soc. 1994, 116, 3615. (e) Zhang, C.; Song, Y. L.; Kühn, F. E.; Wang, Y. X.; Xin, X. Q.; Herrmann, W. A. Adv. Mater. 2002, 14, 818. (f) Zhang, C.; Song, Y. L.; Fung, B. M.; Xue, Z. L.; Xin, X. Q. Chem. Commun. 2001, 843.

(4) Niu, Y. Y.; Zheng, H. G.; Hou, H. W.; Xin, X. Q. Coord. Chem. Rev. 2004, 248, 169.

(5) (a) Lang, J. P.; Xu, Q. F.; Zhang, W. H.; Li, H. X.; Ren, Z. G.; Chen, J. X.; Zhang, Y. Inorg. Chem. 2006, 45, 10487. (b) Lang, J. P.; Jiao, C. M.; Qiao, S. B.; Zhang, W. H.; Abrahams, B. F. Inorg. Chem. 2005, 44, 3664.

(6) (a) Liang, K.; Zheng, H. G.; Song, Y. L.; Lappert, M. F.; Li, Y. Z.; Xin, X. Q.; Huang, Z. X.; Chen, J. T.; Lu, S. F. Angew. Chem., Int. Ed. Engl. 2004, 43, 5776. (b) Huang, K. X.; Song, Y. L.; Pan, Z. R.; Li, Y. Z.; Zhuo, X.; Zheng, H. G. Inorg. Chem. 2007, 46, 6233.

(7) Manoli, J. M.; Potvin, C.; Sécheresse, F.; Marzak, S. Chem. Commun. 1986, 1557.

(8) Zhang, C.; Song, Y. L.; Xu, Y.; Fun, H. K.; Fang, G. Y.; Wang, Y. X.; Xin, X. Q. J. Chem. Soc., Dalton Trans. 2000, 2823.

(9) Lang, J. P.; Xu, Q. F.; Yuan, R. X.; Abrahams, B. F. Angew. Chem., Int. Ed. 2004, 43, 4741.

(10) Characterization for 1: Anal. Calcd. for $\mathrm{C}_{18} \mathrm{H}_{36} \mathrm{Cu}_{3} \mathrm{~N}_{3} \mathrm{~S}_{4} \mathrm{~W}$ (\%): C, 27.12; H, 4.55; N, 5.27. Found C, 27.15; H, 4.57; N, 5.25. IR data (KBr pellets, $\left.\mathrm{cm}^{-1}\right)$ : 2151(vs), 1477(s), 1378(s), 882(s), 738(s), 464(vs), 436(vs).

(11) Crystallographic data for $\mathrm{C}_{18} \mathrm{H}_{36} \mathrm{Cu}_{3} \mathrm{~N}_{3} \mathrm{~S}_{4} \mathrm{~W} \mathbf{1}: M=797.27$, tetragonal, space group $P 4_{3} 2_{1} 2, a=10.9115(15), b=10.9115(15), c=23.638(5)$ $\AA, V=2814.4(8) \AA^{3}, Z=4, T=293(2) \mathrm{K}, D_{\mathrm{c}}=1.882 \mathrm{~g} \mathrm{~cm}^{-3}, \mu($ Mo$\mathrm{K} \alpha)=6.617 \mathrm{~mm}^{-1}, 3112$ reflections measured, 2758 unique $\left[R_{\text {(int) }}=\right.$ $0.0707]$ which were used in the calculations. The final $R_{1}=0.0641, w R_{2}$ $=0.1220$ for 1682 reflections with $I>2 \sigma(I)$ and 134 variable parameters,

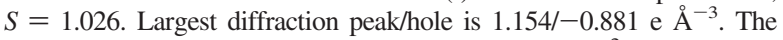
structure was solved by direct methods and refined on $F^{2}$ by full-matrix least-squares techniques.

(12) (a) Moulton, B.; Zaworotko, M. J. Chem. Rev. 2001, 101, 1629. (b) O'Keeffe, M.; Eddaoudi, M.; Li, H. L.; Reineke, T.; Yaghi, O. M. J. 
Solid State Chem. 2000, 152, 3. (c) Bi, M. H.; Li, G. H.; Zou, Y. C.; Shi, Z.; Feng, S. H. Inorg. Chem. 2007, 46, 604.

(13) Manoli, J. M.; Potvin, C.; Sécheresse, F.; Marzak, S. Inorg. Chim. Acta 1988, 150, 257.

(14) Sheik-Bahae, M.; Said, A. A.; Wei, T. H.; Hagan, D. J.; van Stryland, E. W. IEEE J. Quantum Electron. 1990, 26, 760.

(15) (a) Zhang, W. H.; Chen, J. X.; Li, H. X.; Wu, B.; Tang, X. Y.; Ren, Z. G.; Zhang, Y.; Lang, J. P.; Sun, Z. R. J. Organomet. Chem. 2005, 690, 394. (b) Zhang, C.; Song, Y. L.; Jin, G. C.; Fang, G. Y.; Wang, Y. X.; Raj, S. S. S.; Fun, H. K.; Xin, X. Q. J. Chem. Soc., Dalton Trans. 2000, 1317. (c) Zhang, C.; Song, Y. L.; Kühn, F. E.; Xu, Y.;
Xin, X. Q.; Fun, H. K.; Herrmann, W. A. Eur. J. Inorg. Chem. 2002, 55. (d) Zhang, C.; Song, Y. L.; Wang, X.; Kühn, F. E.; Wang, Y. X.; Xu, Y.; Xin, X. Q. J. Mater. Chem. 2003, 13, 571. (e) Cai, Y.; Song, Y. L.; Zheng, H. G.; Niu, Y. Y.; Du, C. X.; Xin, X. Q. Chem. Lett. 2002, 508. (f) Zheng, H. G.; Leung, W. H.; Tan, W. L.; Long, D. L.; Ji, W.; Chen, J. T.; Xin, F. B.; Xin, X. Q. J. Chem. Soc., Dalton Trans. 2000, 2145. (g) Niu, Y. Y.; Song, Y. L.; Zheng, H. G.; Long, D. L.; Fun, H. K.; Xin, X. Q. New J. Chem. 2001, 25, 945.

CG700877N 